\title{
Vibro stone columns - model tests vs. fem calculations
}

\section{W.J. WEHR}

Technical University of Dresden

Institute for geotechnical engineering

George-Bähr-Str.

01069 Dresden, Germany

Research on the group action of stone columns points out that the behaviour of an isolated single column is quite different from the one of a stone column in a group of columns under a rigid footing. To highlight the differences, model tests of a rigid footing on a single sand column in clay and model tests of a rigid footing with various numbers of sand columns in clay are compared. A re-calculation of model tests has been performed by means of the finite element method taking into account the mean grain diameter. Beginning with a single isolated column, the deformation mechanism of the column has been reproduced, detecting a wedge shaped shear zone below the footing. Furthermore, the same footing has been analysed to study the group effect in a section of 5 columns. Again the same deformation mechanism as in the model test has been observed displaying a wedge shaped area below the footing. The influence of the length of the columns and an additional row of columns outside the footing has been investigated and recommendations are given.

Mots-clés : ground improvement, vibro, stone columns.

\section{Colonnes ballastées essais en modèle réduit et calculs aux éléments finis}

L'analyse du fonctionnement de colonnes ballastées en groupe montre que le comportement d'une colonne ballastée isolée est notablement différent de celui d'une colonne ballastée en groupe sous une semelle rigide. Pour mettre en évidence ces différences, des essais en modèle réduit d'une semelle rigide sur une colonne isolée dans l'argile et d'autres essais sur une semelle rigide reposant sur différents nombres de colonnes dans l'argile sont comparés. Les essais ont été recalculés par la méthode des éléments finis, en prenant en compte le diamètre moyen des grains. En commençant par une colonne isolée, le mécanisme de déformation a été reproduit, permettant de déceler une zone de cisaillement en forme de coin sous la semelle. Par la suite, la même semelle a été analysée pour étudier l'effet de groupe dans une section de 5 colonnes. Là encore, le même mécanisme de déformation que dans le modèle réduit a été observé, avec une surface en forme de coin sous la semelle. L'influence de la longueur des colonnes et d'une rangée supplémentaire de colonnes à l'extérieur de la semelle a été étudiée, et des recommandations sont proposées.

Key words: amélioration de sol, procédés de vibration, colonnes ballastées. 


\section{Introduction}

It was observed by various authors (Witt, 1978; Brauns, 1978, 1980; Hu, 1995; Wood, 1998) that shear zones appear during the deformation of stone columns. Therefore, it is essential for the calculation of forces and displacements which depend on the thickness of a shear zone (Tejchman et al., 1998), to model shear zones correctly. The influences of different parameters like initial density, pressure level and mean grain diameter on the width of the shear zone was studied intensively with model tests (Tejchman, 1989; Hammad, 1991; Hassan, 1995) and could be reproduced with FE-calculations (Tejchman, 1997; Tejchman et al., 1998).

Considering a shear deformation problem, a granular material tends to change its volume (either contract or dilate). If the material is in an initially dense state, it increases its volume (dilates). But if this dilatancy is constrained, very high forces may develop. In the case of stone columns, the dilatancy in the shear zones is partly constrained by the stones around the shear zone and the soil surrounding the columns. The understanding of this principle of the constrained dilatancy is important not only for a footing on stone columns (Wehr, 1998), but as well for footings on sand (Herle and Tejchman, 1997), piled raft foundations, sand anchors (Wehr, 1997; Wehr et al., 1997), conventional anchors and nails, piles (Tejchman, 1989), silos (Tejchman, 1997) and blast furnaces (Zaimi, 1998).

Model tests of a single isolated column and a group of columns are outlined first in this paper, and the most important parameters influencing the bearing capacity of the columns are discussed. Afterwards, the tests are recalculated with an elasto-plastic constitutive law within a Cosserat continuum.

\section{2}

\section{Model tests}

\section{$3 \times$}

\section{Single isolated columns}

Model tests with a single isolated sand column in clay were performed (Witt, 1978 ; Brauns, 1978, 1980). Concerning the soils of the model tests, reconstituted Ahrtal clay of high plasticity (PI $=36$ ) with an average undrained cohesion of $C_{u}=18 \mathrm{kPa}$, void ratio of $\mathrm{e}=1.0$, and water content of $30 \%$ and a poorly graded medium Karlsruhe sand $\left(d_{50}=0.4 \mathrm{~mm}, e_{\max }=0.83, e_{\min }\right.$ $=e=0.57$ ) were used. A testing cylinder with a diameter of $152 \mathrm{~mm}$ and a height of $200 \mathrm{~mm}$ was chosen. The diameter of the sand column $d$ was $32 \mathrm{~mm}$ and its length was equal to the height of the clay layer, $\mathrm{h}=200 \mathrm{~mm}$.

The preparation of the test was started by pressing the testing cylinder without bottom into a homogeneous clay sample. Afterwards a centric circular hole for the sand column was achieved with a steel tube which was pressed into the clay. The clay inside the cylinder was removed by a small helical auger. After reaching the lower end of the testing cylinder, the steel tube was lifted, filled with sand which was compacted by a falling weight. When the column was completed, the sand column was charged vertically with a displacement controlled piston using a constant velocity of $0.5 \mathrm{~mm} / \mathrm{min}$.

A cross-section of a deformed column for the first case is shown in figure 1. To visualise the displacements, equally spaced horizontal layers of sand were marked in grey. After a vertical displacement $u$ equal to $10 \%$ of the column diameter $d_{c^{\prime}}$ a peak in the forcedisplacement curve was observed. Until this point a nearly cylindrical expansion of the upper part of the column was observed. After the peak, the force dropped to the residual value of $92 \%$ of its initial value, and later at $20 \%$ of $d_{c}$ the force started to rise slowly again. It can be stated that no sudden failure occurred. After the peak, a change of the deformation mode was observed. Shear zones in the column were created which were approximately inclined 65 degrees to the horizontal. Due to the vertical movement of a wedge shaped part inside the column, the adjacent sand displaced radially. This led to bulging in the upper part of the column.

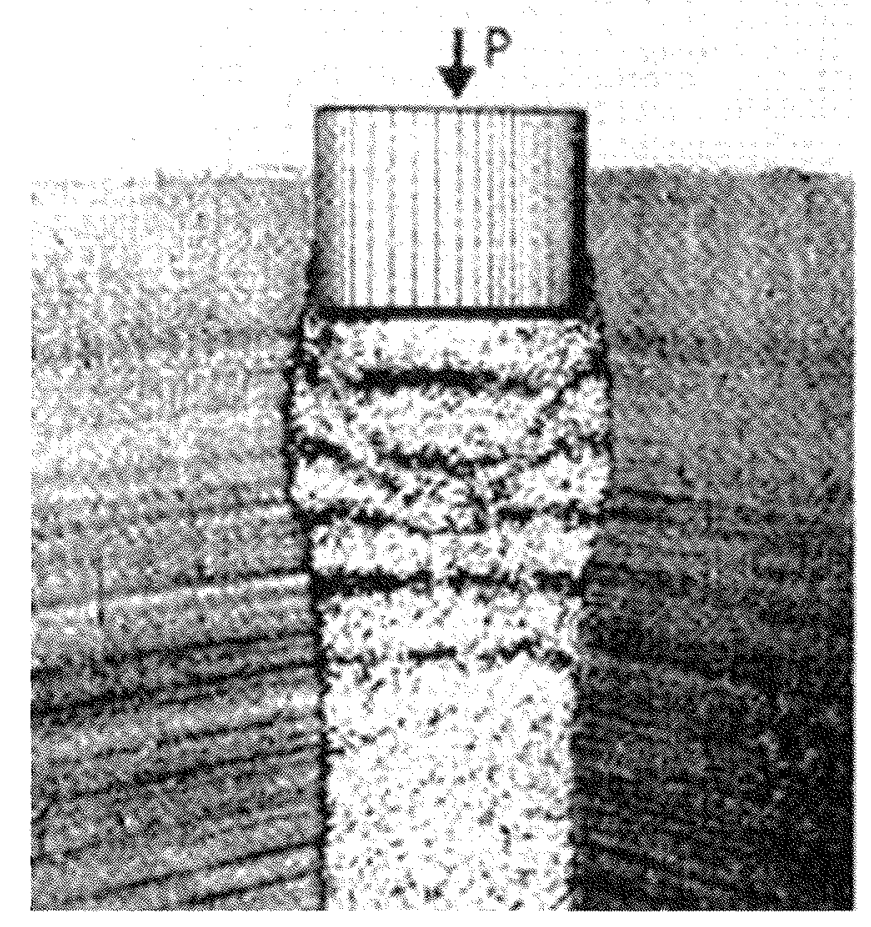

F6. 1 Deformed isolated column, upper part (Brauns, 1980).

\section{Groups of columns}

Model tests with groups of sand columns in clay have been executed by $\mathrm{Hu}$ (1995) and Wood (1998) to get a closer insight into the deformation mechanisms of a group of stone columns under a rigid footing. The soils of the model tests are Speswhite kaolin clay which was reconstituted from slurry with a plasticity index of 27, an average undrained cohesion of $c_{u}=13 \mathrm{kPa}$ and a poorly graded medium Loch Aline sand $\left(d_{50}=0.32 \mathrm{~mm}\right.$, $e_{\text {max }}=0.80, e_{\text {min }}=0.56,0.67<\mathrm{e}<0.74$ ). A testing cylinder with diameter and height of $300 \mathrm{~mm}$ was chosen. 
Using a square column grid, the diameter of the sand columns was $11 \mathrm{~mm}$ and $17.5 \mathrm{~mm}$ and their length varied between $100 \mathrm{~mm}$ and $170 \mathrm{~mm}$. The diameter of the footing has been always kept constant $(100 \mathrm{~mm})$. In this way the influences of the size of the area underneath the footing improved by sand columns and of the length of the sand columns could be studied. In all tests one or two additional rows of columns outside the footing were used because these columns provided a certain degree of confinement (Hu, 1995). However, the beneficial influence was not proved with the tests.

The main result in terms of the deformation under the footing is that a wedge shaped body is displaced vertically in connection with bulging and "buckling" of the columns (see Fig. 2a). "Buckling" was observed near the edges of the footing close to the ground surface and bulging occurred under the center of the footing in a deeper region. The columns around the footing showed a small amount of bending.

The load bearing mechanism is significantly influenced by the length of the columns as compared to the diameter of the footing $D$. If the length of the columns is less than or equal to $D$, the base of the columns will transfer their load to the underlying clay resulting in a significant punching of the column, (Fig. 2b). But if the length of the columns is larger than $1.5 \mathrm{D}$ the penetration of the columns into the clay is insignificant.

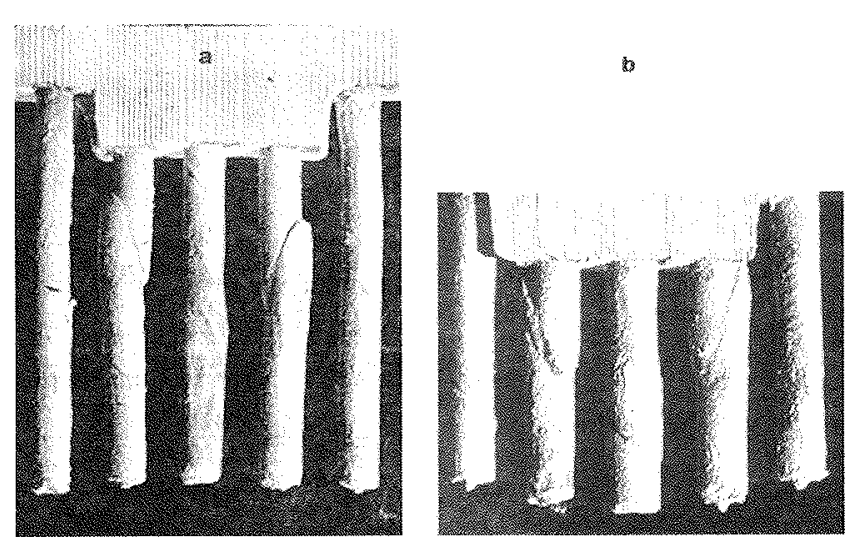

FG. 2 a) Deformed group of long slender columns and b) short thick columns (Hu, 1995).

\section{Elasto-plastic model}

The Cosserat elasto-plastic constitutive model used here includes isotropic hardening and softening. It has been proposed by Muehlhaus (1987) and is described in detail by Tejchman $(1989,1997)$ and Tejchman/Wu (1993). Differences from the conventional theory of plasticity are the presence of Cosserat rotations and couple stresses using the mean grain diameter as a characteristic length.

Twelve material parameters are needed to characterise a soil material: cohesion $c$, friction angle at peak $\varphi_{p}$ and in the critical state $\varphi_{c^{\prime}}$ angle of dilatancy $\beta=\beta_{1}$ $\left(\sin \varphi-\sin \varphi_{c}\right)$, modulus of elasticity, Poissons ratio $\nu$, shear strains at the peak $\gamma_{3}$ and at the beginning of shearing $\gamma_{0}$ mean grain diameter $d_{50}$ and three Cosse- rat-constants $a_{1}$ to $a_{3}$. In Table 1 , the parameters of the elasto-plastic model for the two materials considered in recalculations of model tests are summarized. The parameters for Karlsruhe sand have been determined by Tejchman (1997) and the parameters for Ahrtal clay has been estimated from the material parameters given by Witt (1978).

\begin{tabular}{|c|c|c|c|c|c|}
\hline \multirow[t]{2}{*}{13} & \multirow[t]{2}{*}{ TABLE I } & \multicolumn{4}{|c|}{$\begin{array}{l}\text { Material parameters for the elasto-plasti } \\
\text { model. }\end{array}$} \\
\hline & & c. & (6) & 9 & B \\
\hline & & {$[\mathrm{kPa}]$} & {$[\operatorname{deg}]$.} & [deg.] & {$[--]$} \\
\hline sand & & 0 & 40 & 35 & 3 \\
\hline clay & & 20 & 0 & 0 & 0 \\
\hline & & E & V & 3 & th \\
\hline & & {$[\mathrm{MPa}]$} & {$[--]$} & {$[--]$} & {$[--]$} \\
\hline sand & & 50 & 0.30 & 0.05 & 0.03 \\
\hline clay & & 5 & 0.45 & 0.05 & 0.03 \\
\hline & & (1.) & a. & a. & $\sqrt{2} \cdot 3$ \\
\hline & & {$[\mathrm{mm}]$} & {$[--]$} & {$[--\cdot]$} & {$[--]$} \\
\hline sand & & 0.4 & 0.375 & 0.125 & 1.00 \\
\hline clay & & 0.002 & 0.375 & 0.125 & 0.25 \\
\hline
\end{tabular}

\section{Calculations}

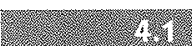

\section{Single isolated columns}

A single isolated sand column in clay was modelled with FEM and a polar elasto-plastic constitutive law under plane strain conditions. The considered dimensions of the sand column were $200 \mathrm{~mm}$ height and $16 \mathrm{~mm}$ width due to the symmetry of the system. They correspond to the column diameter of $32 \mathrm{~mm}$ in the model tests.

In total, 1,024 three-noded triangular elements with three degrees of freedom in each node and with linear shape functions were adopted. The integration was performed with one sampling point in the middle of each element. The calculations were carried out with large deformations and curvatures. A quasi-static deformation was initiated through constant vertical displacement increments $\Delta u$ prescribed at the nodes along the top of the sand column.

Fig. 3a shows the upper part of the deformed single column after a displacement $u=10 \mathrm{~mm}$. The lower part is not shown, because it has not been deformed. If this figure is compared with Fig. 1, a shear zone can be identified insicle the column with the same inclination. The calculated width of the shear zone extends over more than one element contrary to a classical continuum (Tejchman, 1989). This results in a realistic mesh independent width of the shear zone.

The exact width and location of the shear zone is indicated by the Cosserat rotations shown in Fig. $3 \mathrm{~b}$ yielding a thickness of $d_{s}=6-8 \mathrm{~mm}$ or $15-20 d_{50}$ within $3-4$ elements inside the sand column quite similar to the model test (Fig. 1). Another shear zone which 

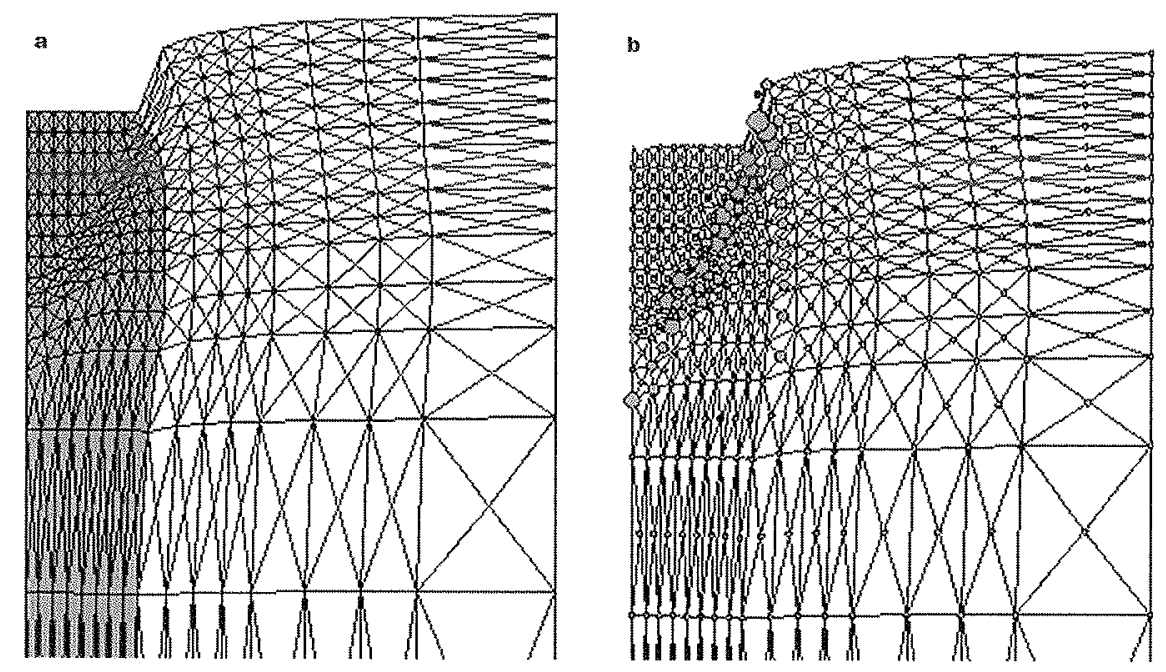

fic. 3 a) Deformed single column with shear zone, upper part, $u=$ $10 \mathrm{~mm}$, clay (white) and column (grey) and b) Cosserat rotations: small circle $\omega_{c}=0.0$, large circle $\omega_{c}=2.5$.

was not observed in the model tests may be seen in Fig. $3 b$ in the first row of elements in the clay next to the column. This shear zone is due to the movement of the sand column relative to the clay starting to form before the shear zone in the sand column develops.

Fig. 4 represents force-displacement curves of the sand column in a model test and calculation. The calculated curve is very close to the one from the model test (dashed line) showing a peak corresponding to a fully developed shear zone inside the column. Both forces decrease first and then rise again slowly after the peak, because the forces are increasing when the footing is displaced deeper into the column after the material softening.

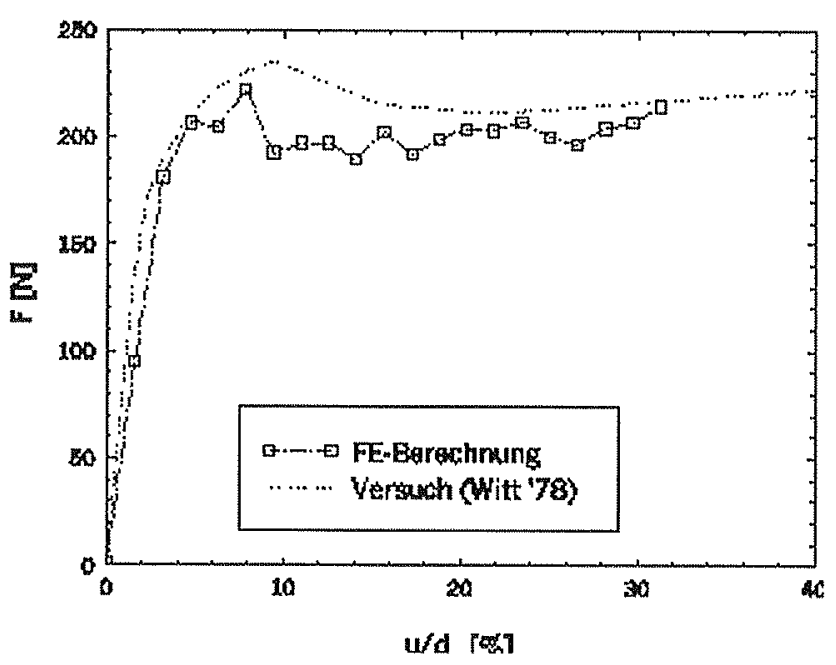

nG. 4 Force-displacement curves of a single isolated sand column in clay, model test by Witt (1978) as dashed line and FE-calculation.

It is concluded, that FE-calculations of sand columns in clay yield qualitatively and quantitatively realistic results. The important effects which have been observed in the model tests were described with a polar elasto-plastic constitutive law and the Cosserat continuum.

\section{2}

\section{Group of columns}

The aim of this section is to show, that the deformation mechanism of a rigid footing on a group of columns is different from that on a single column. In order to compare both cases, the FE-mesh of section 4.1 and the soil parameters have not been changed but some sand elements were substituted by clay elements. Only 2.5 sand columns were modelled using the symmetry of the system.

Fig. 5a shows the upper part of the deformed group of columns after a displacement $u=10 \mathrm{~mm}$. If these results are compared with Fig. 2a, a wedge shaped part of the soil below the footing nearly undergoes no deformation. The edge of this wedge consists of a shear zone partly inside the sand columns and partly in the clay having the same inclination in the model tests and the calculations. Different deformations are observed in the center column which bulges, and in the middle and outer column where a shear zone is observed. This corresponds exactly to the observations made during the model tests by Hu 1995.

The calculated width of the shear zone in Fig. 5b extends over just 2 elements with a thickness of $d_{s}=4 \mathrm{~mm}\left(10 d_{50}\right)$ which is smaller than the calculated width of the shear zone in a single column (Fig. 3b).

Shear zones in the clay which were not observed in the model tests, may be seen in Fig. 3b between all columns and outside the column under the edge of the footing. Note, that these shear zone extends only to a limited depth depending on the movements of the columns relative to the clay.

An interesting question from the practical point of view is which length $l$ of the sand columns is sufficient to carry a certain footing load with a footing diameter $D$. To investigate this problem, the length of the columns has been reduced stepwise from $20 \mathrm{~cm}$ $(l / D=6.3)$ to $3.6 \mathrm{~cm}(I / D=1.1)$. It has been found that there is only a negligable difference in the force-displacement curves and the deformation mechanism if the length is reduced from $20 \mathrm{~cm}(1 / D=6.3)$ to $5.4 \mathrm{~cm}$ 

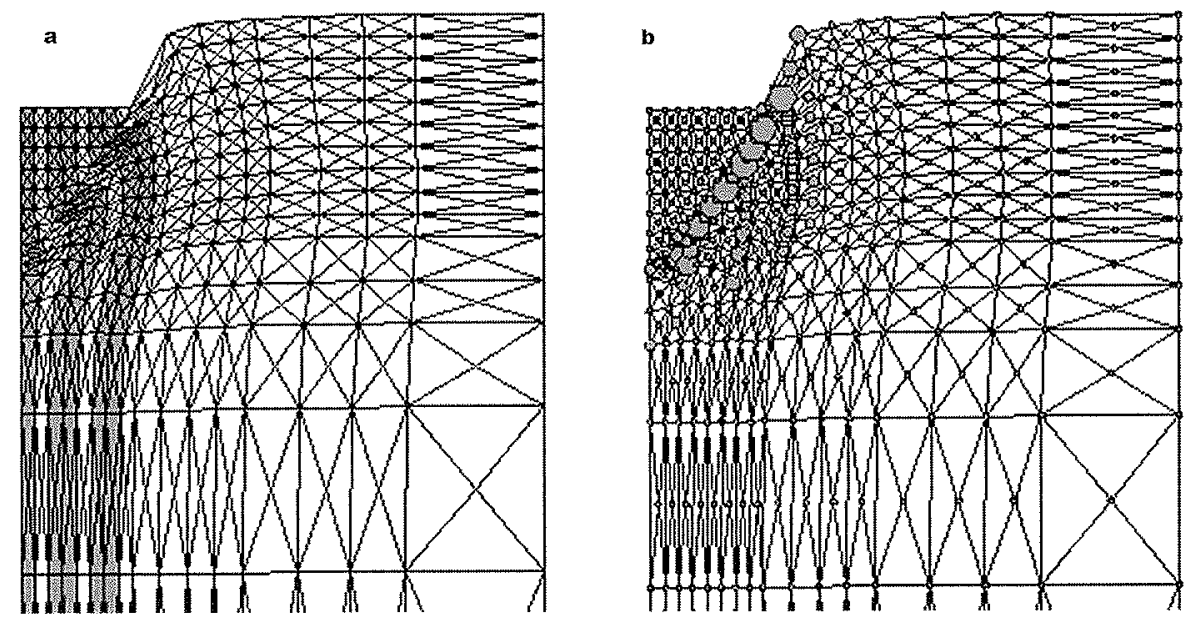

Fis. 5 a) Deformed group of long slender columns, upper part, $u=$ $10 \mathrm{~mm}$, clay (white) and column (grey) and b) Cosserat rotations: small circle $\omega_{c}=\mathbf{0 . 0}$, large circle $\omega_{c}=3.3$.

$(V D=1.7)$. But if a further reduction is made to $3.6 \mathrm{~cm}$ $(/ / D=1.1)$ the deformation mechanism involves significant punching of the column bases into the clay, see Fig. 6. The same transition from "buckling" to "bulging" with punching of the column bases has been observed in the model tests, Fig. 2 at about $l / D=1.5$. The width of the main shear zone adjacent to the wedge becomes larger for short columns $(l / D=1.1)$ with a thickness of $d_{s}=6-8 \mathrm{~mm}$ or $15-20 d_{50}$. This has been called "bulging" by $\mathrm{Hu}, 1995$ but there are only shear zones having a different width. The ratio $/ / D=1.5$ is most likely not a constant value, but dependant on the chosen soil parameters. The smaller $c_{u}$ of the clay, the longer the columns have to be chosen. More detailed research is necessary in the future.

Another important question is, if it is necessary to use additional columns outside the footing area. The FE-mesh with one additional column outside the footing is shown in Fig. $6 \mathrm{~b}$ after a deformation of $u=10 \mathrm{~mm}$. Comparing the FE-mesh with the model test in Fig. 2a no shear zone is observed in the additio- nal column in both cases. The small distortion at the very top of the column is due to the fact, that in reality the edge of the sand column loses its contact with the clay which has been neglected in the calculations.

The peak forces with and without the additional column are $240 \mathrm{~N}$ and $225 \mathrm{~N}$ respectively, representing an increase of only $7 \%$. This amount depends of course on the soil parameters and more research is necessary to study this in detail.

\section{5 \\ Conclusions}

Recent research on the group action of stone columns points out that the behaviour of an isolated single column is quite different from the one of a group of columns under a rigid footing. To highlight the differences, model tests with a single sand column in clay and model tests with groups of sand columns in
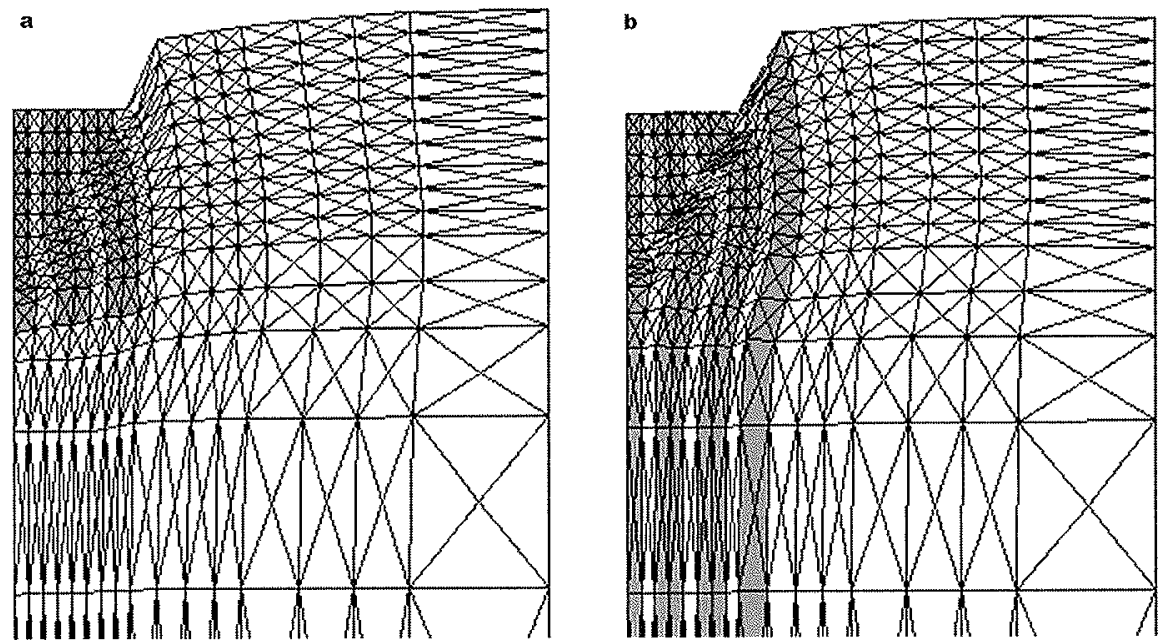

a) Deformed group of short columns, upper part, $u=10 \mathrm{~mm}$, clay (white) and column (grey) and b) deformed group of long slender columns with additional column outside the footing, upper part, $\mathrm{u}=10 \mathrm{~mm}$, clay (white) and column (grey). 
clay under a rigid footing are compared. The deformations of columns depend on the existence and position of shear zones inside the columns.

A re-calculation of the tests has been performed by means of the finite element method with an elastoplastic constitutive law within the Cosserat continuum. In this way, the mean grain diameter which is essential to capture shear zones, is taken into account. Beginning with a single isolated column, the deformation mechanism of the column and the force-displacement curve is reproduced very well, detecting a wedge shaped shear zone below the footing.

Additionally, the same footing has been taken to study the group effect with 5 columns. Again the same deformation mechanism as in the model test has been observed displaying a wedge shaped area below the footing. The borders of this wedge passing through the columns and the clay represent shear zones. Furthermore, calculated shear zones in clay adjacent to all columns extend down to a limited depth where there is no relative movement between the columns and the clay.

The length of the columns has been varied to investigate their influence. A significant penetration of the columns into the clay has been calculated and measured if the length of the columns is less than 1.5 times the diameter of the footing. In the model tests, an extra row of columns has been used next to the footing but their influence on the bearing capacity seems to be rather low according to the calculations. Most likely the length of the columns and the number of increasing column rows adjacent to the footing have to be increased with decreasing $c_{u}$ of the surrounding soil.

\section{References}

Brauns J. - Die Anfangstraglast von Schottersäulen im bindigen Untergrund. Die Bautechnik, 1978, 263-270.

Brauns J. - Untergrundverbesserung mittels Sandpfählen oder Schottersäulen. Der Tiefbau, 1980, vol. 8, 678-683.

Hammad W. - Modélisation non linéaire et étude expérimentale des bandes de cisaillement dans les sables. PhD. Thesis, University of Grenoble,IMG, Labo 3S, 1991.

Hassan A.H. - Étude expérimentale et numérique du comportement local et global d'une interface sol granulairestructure. PhD. Thesis, University of Grenoble, IMG, Labo 3S, 1995.

Herle I., Tejchman J. - Effects of grain size and pressure level on bearing capacity of footings on sand. Int. Symposium on Deformation and Progressive Failure in Geomechanics, 5-7 Oct. 1997, Nagoya, Japan, 1997, 781-786.

Hu W. - Physical modelling of group behaviour of stone column foundations. $\mathrm{PhD}$ thesis, University of Glasgow, 1995.

Muehlhaus H.B. - Berücksichtigung der Inhomogenitäten im Gebirge im Rahmen einer Kontinuumstheorie. Publications of the Institute of soil and rock mechanics, University of Karlsruhe, 1987, n 106.
Tejchman J. - Scherzonenbildung und Verspannungseffekte in Granulaten unter Berücksichtigung von Korndrehungen. Publications of the institute of soil and rock mechanics, University of Karlsruhe, $1989, n^{\circ} 117$.

Tejchman J. - Modelling of shear localisation and autogeneous dynamic effects in granular bodies. Publications of the institute of soil and rock mechanics, University of Karlsruhe, 1997, $\mathrm{n}^{\circ} 140$.

Tejchman J. - Numerical modelling of shear localisation with a polar hypoplastic approach. Localisation and Bifurcation Theory for Soils and Rocks, Editors: T. Adachi, F. Oka, A. Yashima, A.A. Balkema, 1989, 323-332.

Tejchman J., Wu W. - Numerical study on patterning of shear bands in a Cosserat continuum. Acta Mechanica, Springer Verlag, vol. 99, 1993, 61-74.

Tejchman J., Herle I., Wehr W. - FE-studies on the influence of initial void ratio, pressure level and mean grain diameter on shear localisation. Int. Journal for Numerical and Analytical Methods in Geomechanics, 1998.

Wehr W. - Granular anchors in rock and soil. 10th European Young Geotechnical Engineers19 Conference, Izmir/Turkey, 1997, 179-185.
Wehr W., Tejchman J., Herle I., Gudehus G. -- Sand anchors: a shear zone problem. Int. Symposium on Deformation and Progressive Failure in Geomechanics, 5-7 Oct. 1997, Nagoya, Japan, 1997, 787-792.

Wehr W. - Granulatumhüllte Anker und Nägel-Sandanker. Publications of the institute of soil and rock mechanics, University of Karlsruhe, 1998, n 145.

Witt K.J. - Versagensmechanismus einzeln belasteter Schottersäulen im bindigen Untergrund bei plötzlicher Belastung. B.Sc. thesis, institute of soil and rock mechanics, University of Karlsruhe, 1978.

Wood D.M., Hu W. - Mechanisms of load transfer deduced from failure modes of model stone column foundations. Int. Symposium on Deformation and Progressive Failure in Geomechanics, Nagoya, Japan, 1997, 799-804.

Zaimi S.A. - Modélisation d'écoulement des charges dans le haut fourneau. $\mathrm{PhD}$ thesis, Ecole centrale Paris, France, 1998. 